\title{
The Dilute Magnetic and Optical Properties of Mn-Doped ZnO Nanowires
}

\author{
Xiying $\mathrm{Ma}^{1,2}$ and Caoxin Lou ${ }^{1}$ \\ ${ }^{1}$ School of Mathematics and Physics, Suzhou University of Science and Technology, 1701 Binhe Road, Jiangsu, Suzhou 215011, China \\ ${ }^{2}$ Institute of Photoelectrical Materials, Shaoxing University, Zhejiang Province, Shaoxing 312000, China
}

Correspondence should be addressed to Xiying Ma, maxy@usx.edu.cn

Received 14 March 2011; Revised 4 July 2011; Accepted 13 July 2011

Academic Editor: Edward Andrew Payzant

Copyright ( $) 2011$ X. Ma and C. Lou. This is an open access article distributed under the Creative Commons Attribution License, which permits unrestricted use, distribution, and reproduction in any medium, provided the original work is properly cited.

\begin{abstract}
We present a study of the dilute magnetic and optical properties of Mn-doped $\mathrm{ZnO}$ nanowires (Nws) fabricated by means of a liquid phase evaporation deposition process. The samples were grown using a mixed $\mathrm{Zn} / \mathrm{Mn}$ liquid source with a mol ratio of $\mathrm{Mn} 10 \%$ in a constant $\mathrm{O}_{2} / \mathrm{Ar}$ gas at $580^{\circ} \mathrm{C}$. The nanowires show a strong UV emission at $405 \mathrm{~nm}$ and a blue emission at $433 \mathrm{~nm}$ in the photoluminescence spectrum. In addition, they present a strong reversible smooth ferromagnetic hysteresis loop at room temperature, and the corresponding saturation magnetization $\mathrm{M}_{\mathrm{s}}$ is up to $0.015 \mathrm{emu} / \mathrm{g}$ Oe, showing that the nanowires are of a ferromagnetism semiconductor (DMS). With the strong magnetic and photoluminescence properties, $\mathrm{ZnO}$ : Mn Nws will be used in fields of making electromagnetic devices and magneto-optical storage devices.
\end{abstract}

\section{Introduction}

Zinc-oxide-( $\mathrm{ZnO}-)$ based dilute magnetic semiconductors (DMSs) have attracted great research interest for having a great potential of making various room temperature electromagnetic devices $[1,2]$. Now, theoreticians have identified $\mathrm{ZnO}$ as an excellent candidate host semiconductor for supporting high-Curie-temperature $\left(T_{C}\right)$ ferromagnetism when doped with a variety of $3 \mathrm{~d}$ transition metal ions, particularly Mn [3-7]. Experimentalists have verified these predictions for $\mathrm{Mn}$-doped $\mathrm{ZnO}$ with room-temperature ferromagnetism [8-10]. In fact, $\mathrm{Mn}$-doped $\mathrm{ZnO}$ will be a multifunctional material with coexisting magnetic, semiconducting, and optical properties [3], which would allow tuning the band gap for making UV detector and light emitters. So far, most of the investigations on $\mathrm{ZnO}: \mathrm{Mn}$ have focused on their thin films $[11,12]$ and revealed the ferromagnetism with a $T_{C}$ ranging from $37 \mathrm{~K}$ to $250 \mathrm{~K}[13,14]$. There are few reports on the magnetic properties of $\mathrm{Mn}$-doped $\mathrm{ZnO}$ nanowires $[15,16]$. With the aim of investigation of the magnetism optical properties of $\mathrm{Mn}$-doped $\mathrm{ZnO}$ nanowires, we synthesized $\mathrm{ZnO}: \mathrm{Mn}$ nanowires with ferromagnetic properties at room temperature using a simple liquid phase evaporation deposition process. Our study indicates that the observed ferromagnetism in $\mathrm{ZnO}: \mathrm{Mn}$ nanowires at room temperature can be attributed to the incorporation of transition metal $\mathrm{Mn}$ ions into $\mathrm{ZnO}$ lattice. At the same time, we investigated the optical properties of $\mathrm{ZnO}: \mathrm{Mn}$ nanowires. The surface morphology of the products was investigated by scanning electron microscopy (SEM), and the optical characteristics were determined by photoluminescence (PL) spectra at room temperature.

\section{Experiment}

Mn-doped $\mathrm{ZnO}$ nanowires (Nws) samples were fabricated by a liquid phase evaporation deposition process. The growth system is composed of a large horizontal quartz tube furnace, a vacuum system, a gas meter, and a temperature controller. Si (111) substrates were cleaned ultrasonically with a sequence of acetone, ethanol, and deionized water. Then moved the native $\mathrm{SiO}_{2}$ layer with diluted HF solution and dried by blowing $\mathrm{N}_{2}$. For uniform growth, cleaned $\mathrm{Si}$ (111) substrates were placed at the center of the furnace. Prior to the fabrication, the furnace was pumped to high vacuum of $10^{-4} \mathrm{~Pa}$ and heated to $100^{\circ} \mathrm{C}$ and kept at this temperature for 2 hours to remove any water moisture from 


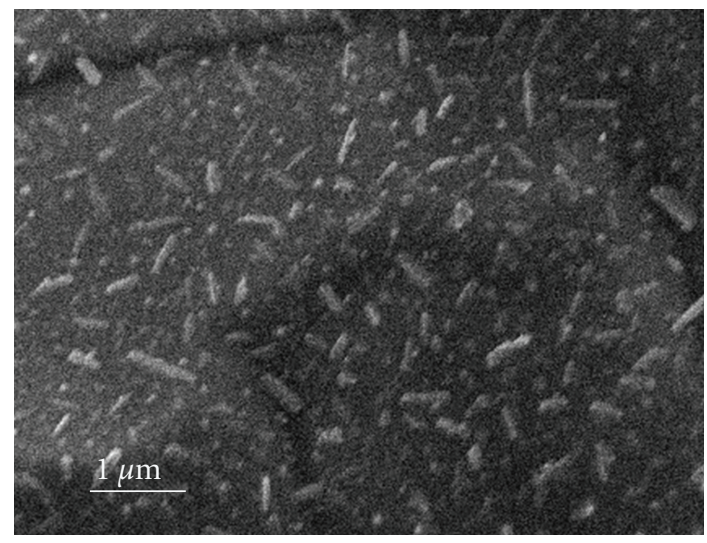

(a)

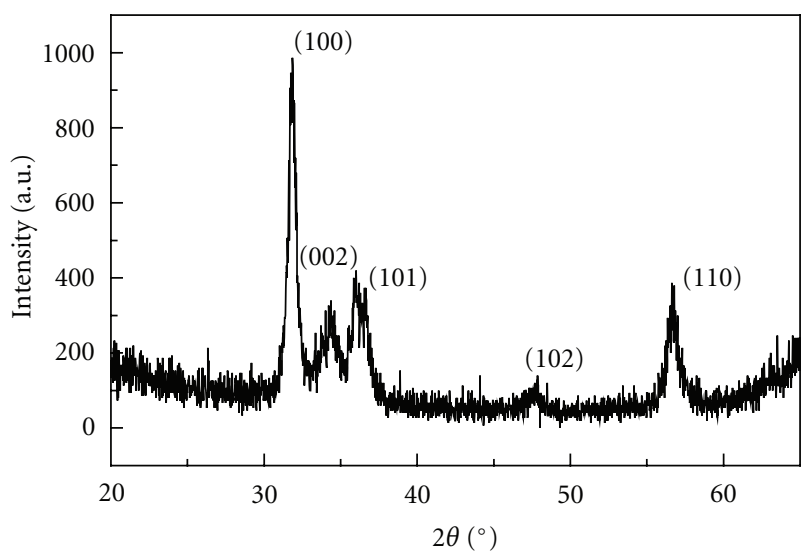

(c)

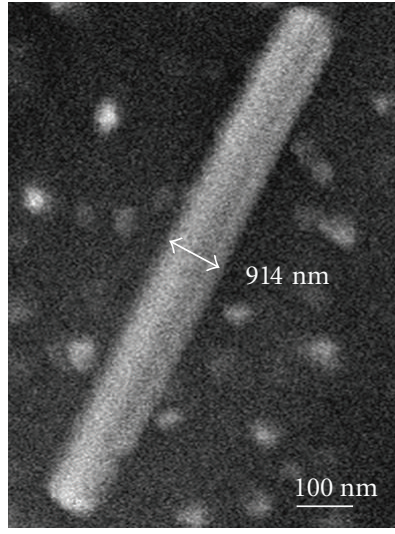

(b)

Figure 1: (a) The surface SEM image of the as-grown Mn-doped ZnO Nws with a Mn mol ratio 10\% on Si substrate; (b) a magnification picture of a single $\mathrm{ZnO}: \mathrm{Mn}$ nanowire with a diameter of $91.4 \mathrm{~nm}$; (c) the X-ray diffraction patterns of $\mathrm{ZnO}: \mathrm{Mn} \mathrm{Nws}$ on Si substrate.

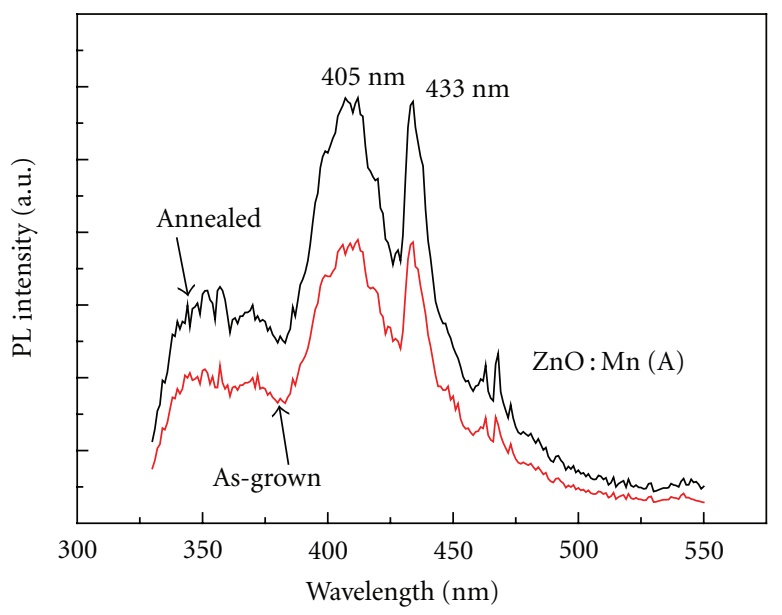

Figure 2: The PL spectra of the as-grown and the annealed $\mathrm{ZnO}: \mathrm{Mn}$ Nws at room temperature, exhibiting strong UV emissions at $405 \mathrm{~nm}$ and a blue emission at $433 \mathrm{~nm}$.

the mixture. Then the furnace was heated to the growing temperature of $580^{\circ} \mathrm{C}$. Zinc acetate dihydrate and manganese acetate tetrahydrate were mixed with a $\mathrm{Mn} / \mathrm{Zn}$ mol ratio of $10 \%$, then hydrolyzed into liquid phase by ethanol and bathed in water at $95^{\circ} \mathrm{C}$ for 30 mins. The compounds took a chemical reaction as follow:

$$
\begin{aligned}
\mathrm{C}_{4} \mathrm{H}_{6} \mathrm{O}_{4} \mathrm{Mn} \cdot 2 \mathrm{H}_{2} \mathrm{O}+\mathrm{C}_{4} \mathrm{H}_{6} \mathrm{O}_{4} \mathrm{Zn} \cdot 2 \mathrm{H}_{2} \mathrm{O} \\
\quad \longrightarrow \mathrm{ZnO}: \mathrm{Mn}+2 \mathrm{C}_{2} \mathrm{H}_{5} \mathrm{O}+5 \mathrm{H}_{2} \mathrm{O}+4 \mathrm{CO}_{2} .
\end{aligned}
$$

$\mathrm{ZnO}$ molecules and $\mathrm{Mn}^{2+}$ ions were carried into the tube by a mixture gas of $\mathrm{O}_{2}$ and $\mathrm{Ar}$ and flowed through the furnace with a constant velocity. They took a chemical reaction and condensed on the substrates. The growth process was carried out for 1 hour and then annealed in situ at $800^{\circ} \mathrm{C}$ for $1 \mathrm{~h}$. Finally, the samples were removed from the furnace when the system was cooled down to room temperature.

The morphology of the products was investigated by a Shimadzu SS-550 super scanning electron microscope (SEM). The composition was analyzed by X-ray diffraction (XRD) on a RINT2000 vertical goniometer with $\mathrm{Cu} \mathrm{K \alpha}$ radiation $(\lambda=0.1541 \mathrm{~nm})$. The photoluminescence $(\mathrm{PL})$ measurement was performed using a $310 \mathrm{~nm}$ excitation source at room temperature. And the magnetism properties are measured by a magnetic gauge at $77 \mathrm{~K}$ and room temperature. 


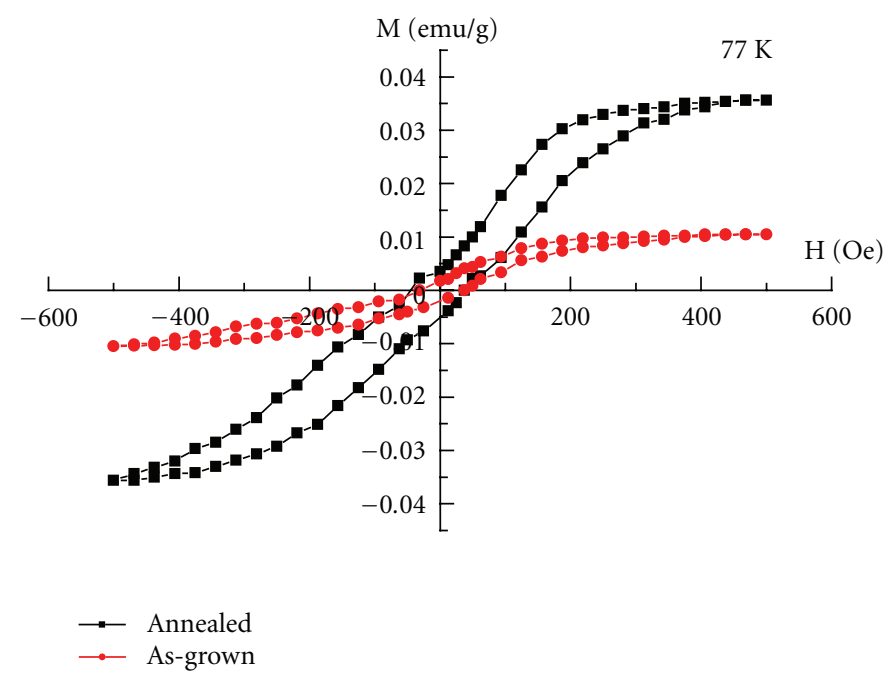

(a)

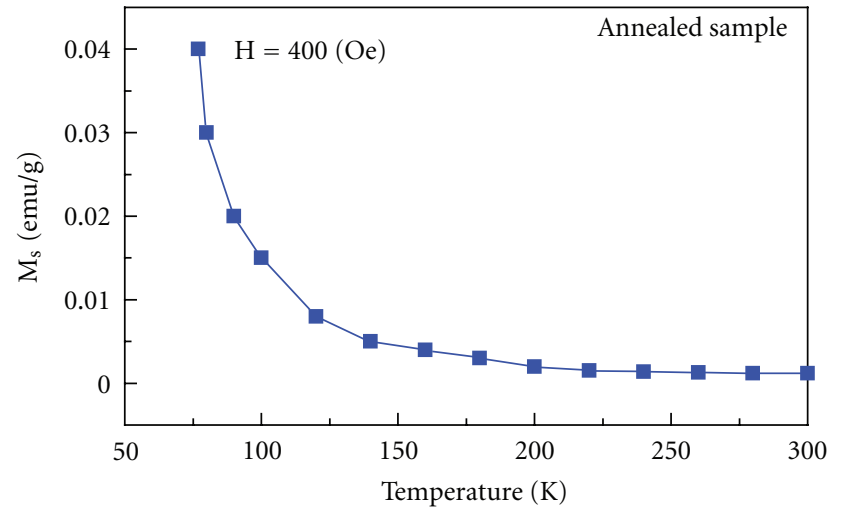

(b)

Figure 3: (a) The magnetism properties of the as-grown and the annealed $\mathrm{ZnO}: \mathrm{Mn}$ Nws at $77 \mathrm{~K}$ with the applied magnetic field $\mathrm{H}$; (b) the temperature dependence of the saturation magnetization $\mathrm{M}_{\mathrm{s}}$ at $\mathrm{H}=400$ Oe.

\section{Result and Discussion}

Figure 1(a) illustrates the typical surface morphology of the as grown $\mathrm{Mn}$-doped $\mathrm{ZnO} \mathrm{Nws}$ as determined by SEM. Many $\mathrm{ZnO}: \mathrm{Mn}$ nanowires are uniformly dispersed on the Si substrate. They have a uniform diameter about $90 \mathrm{~nm}$ but their length varies in a large range of 100 $800 \mathrm{~nm}$. In addition to $\mathrm{ZnO}$ Nws, there are many newly nucleated nanoparticles scatted around the nanowires. This attributes to the long growth process, leading to new particles nucleation continually. Figure $1(\mathrm{~b})$ is a magnification picture of a single $\mathrm{ZnO}: \mathrm{Mn}$ nanowire with a diameter of $91.4 \mathrm{~nm}$. It is very straight and uniform, showing that the nanowire is of high quality. Figure $1(\mathrm{c})$ shows an in-plane $\mathrm{X}$-ray diffraction pattern of the as grown $\mathrm{ZnO}: \mathrm{Mn}$ Nws. The diffraction peaks are located at $31.7^{\circ}, 34.7^{\circ}, 36.7^{\circ}, 47.9^{\circ}$, and $56.4^{\circ}$, corresponding to the (100), (002), (101), (102), and (110) crystal planes of the standard diffraction spectrum of bulk wurtzite $\mathrm{ZnO}$. The intensity of the (100) peak is very strong, almost three times of that (101) and (110), indicating that the growth of $\mathrm{ZnO}$ nanowires predominates in (100) facet. The small diffraction peaks are attributed to the small nanocrystals scattered on the substrate. There are no extra peaks from $\mathrm{Mn}$, showing that the structure of $\mathrm{ZnO}$ remains unchanged for low-doping concentration of $\mathrm{Mn}$. The doped $\mathrm{Mn}^{2+}$ ions simply replace $\mathrm{Zn}$ ions in the structure. From the diffraction peaks, we can confirm that liquid phase synthesized $\mathrm{ZnO}: \mathrm{Mn}$ nanowires have a distinct wurtzite structure.

Figure 2 shows the photoluminescence (PL) spectra of the as grown and the annealed $\mathrm{ZnO}: \mathrm{Mn}$ Nws samples at room temperature. Both of them emit a strong UV emission at $405 \mathrm{~nm}$ and a blue emission at $433 \mathrm{~nm}$. The former emission is considered to be the UV emission of $\mathrm{ZnO}$ band edge emission shifted to a longer wavelength [17], which caused by Mn impurities introducing an impurity level in the band gap of $\mathrm{ZnO}$. The shape of PL spectra of the two samples is very similar, but the PL intensity of the annealed sample is stronger 1.5 times that of the as grown sample. The $\mathrm{ZnO}: \mathrm{Mn}$ Nws samples achieve a very strong UV emission when synthesized through a liquid phase evaporation deposition, showing that the $\mathrm{ZnO}$ Nws are of high quality.

To investigate the dilute magnetic semiconductors (DMSs) properties of $\mathrm{ZnO}: \mathrm{Mn}$ Nws, we measured the magnetization $\mathrm{M}$ with the applied magnetic field $\mathrm{H}$ at $77 \mathrm{~K}$ and room temperature. Figure 3(a) shows the magnetization $\mathrm{M}$ behaviors at $77 \mathrm{~K}$ of the samples. $\mathrm{M}$ initially increases with $\mathrm{H}$ linearly and then slowly arrive their saturation. The saturation value $M_{s}$ is $0.01 \mathrm{emu} / \mathrm{g}$ for the as grown sample and $0.035 \mathrm{emu} / \mathrm{g}$ for the annealed sample. For a reverse magnetic field $\mathrm{H}$, the changing of $\mathrm{M}$ is symmetrical with that of the positive $\mathrm{H}$. Therefore, we observe two narrow and smooth magnetic hysteresis loops as the magnetic field $\mathrm{H}$ changes from -400 to $400 \mathrm{Oe}$. The coercive field strengths $\mathrm{H}_{\mathrm{c}}$ are $0.023 \mathrm{emu} / \mathrm{g}$ and $0.0054 \mathrm{emu} / \mathrm{g}$ for the as grown and the annealed samples, respectively, showing that the $\mathrm{ZnO}: \mathrm{Mn}$ Nws are characteristic of the ferromagnetic materials. Figure 3(b) shows a temperature dependence of the magnetization $\mathrm{M}$ at $\mathrm{H}=400 \mathrm{Oe}$ for the annealed $\mathrm{ZnO}: \mathrm{Mn}$ sample. It decreases quickly from $0.035 \mathrm{emu} / \mathrm{g}$ at $77 \mathrm{~K}$ to $0.001 \mathrm{emu} / \mathrm{g}$ as temperature increased to $300 \mathrm{~K}$. $\mathrm{ZnO}: \mathrm{Mn}$ Nws present a better magnetic signal at low temperatures we can deduce that there are some isolated $\mathrm{Mn}^{2+}$ ions exhibit the ferromagnetism at low temperatures but no ferromagnetism contribution at RT. The results show that $\mathrm{ZnO}: \mathrm{Mn}$ Nws may have some complicate magnetic behavior at low temperatures. It is reasonable to say that the spins of these isolated $\mathrm{Mn}^{2+}$ ions are frozen at room temperatures but give rise to the ferromagnetic component at $77 \mathrm{~K}$. 


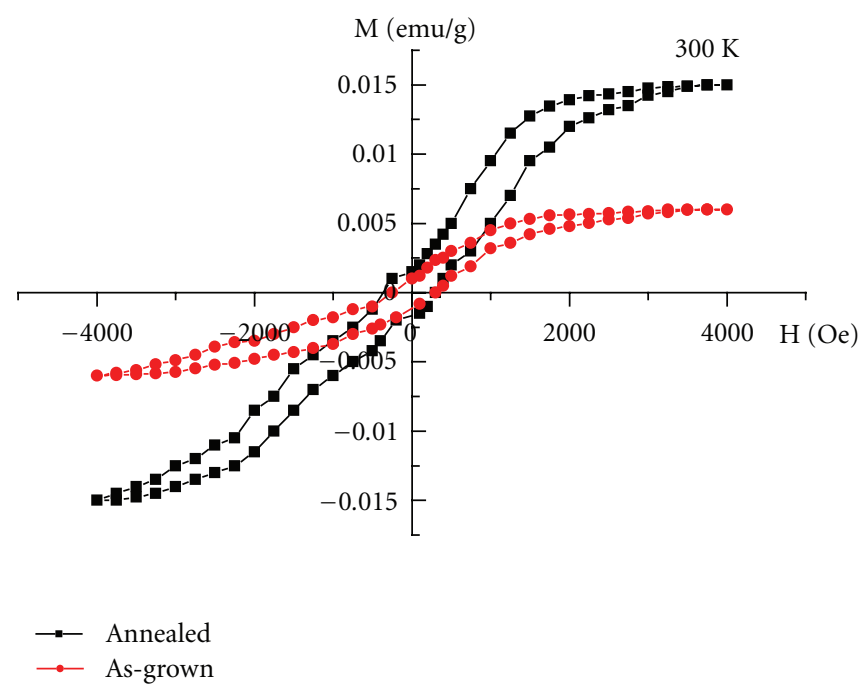

Figure 4: The magnetism properties of the as grown and the annealed $\mathrm{ZnO}$ : Mn Nws at room temperature with the applied magnetic field $\mathrm{H}$.

Figure 4 shows the magnetic properties of the samples at room temperature. Clearly, with an applied magnetic field over 500 Oe, both of the samples show significantly ferromagnetic characters at room temperature. $M$ increases and arrives to the saturation value $M_{s} 0.005 \mathrm{emu} / \mathrm{g}$ and $0.015 \mathrm{emu} / \mathrm{g}$ for the as grown and the annealed samples when $\mathrm{H}$ is up to $4000 \mathrm{~K}$, respectively. The corresponding coercive field strengths $\mathrm{H}_{\mathrm{c}}$ are $2.5 \times 10^{-3} \mathrm{emu} / \mathrm{g}$ and 1.0 $\times 10^{-3} \mathrm{emu} / \mathrm{g}$. These observations consistent with those reported for other ferromagnetic $\mathrm{ZnO}$ and nanocrystalline DMS-quantum dots aggregates $[18,19]$. Similar coexistence of ferromagnetic and paramagnetic moments has been observed in Fe-doped $\mathrm{ZnO}$ systems [10] and $\mathrm{Ni}: \mathrm{ZnO}$ quantum dots [20]. The hysteresis loops at $300 \mathrm{~K}$ indicate that the presence of a ferromagnetic phase in $\mathrm{ZnO}: \mathrm{Mn}$ at room temperature and the steep rise in magnetization seems to be intrinsic to diluted magnetic semiconductors [21].

Figure 5 shows the magnetic conductivity of the as grown and the annealed $\mathrm{ZnO}: \mathrm{Mn}$ Nws at room temperature with the applied magnetic field $\mathrm{H}$. The corresponding maximum values of the magnetic conductivity are $5 \mu_{\mathrm{B}}$ and $2.4 \mu_{\mathrm{B}}$, respectively. That further confirms that $\mathrm{ZnO}: \mathrm{Mn}$ Nws have good ferromagnetism properties.

\section{Conclusion}

Mn-doped ZnO Nws with a diameter of $90 \mathrm{~nm}$ have been grown using a liquid phase evaporation vapor phase deposition. $\mathrm{ZnO}: \mathrm{Mn}$ Nws exhibit a strong dominant UV emission at $408 \mathrm{~nm}$ and a blue emission at $433 \mathrm{~nm}$ at room temperature. Moreover, they present a strong ferromagnetic properties and a narrow and smooth ferromagnetic hysteresis loop as the magnetic field $\mathrm{H}$ changes from -4000 to 4000 Oe at room temperature. The results show that $\mathrm{Zn}: \mathrm{Mn}$ Nws are of strong ferromagnetism and optical properties that can be used as blue light magneto-optical storage material.

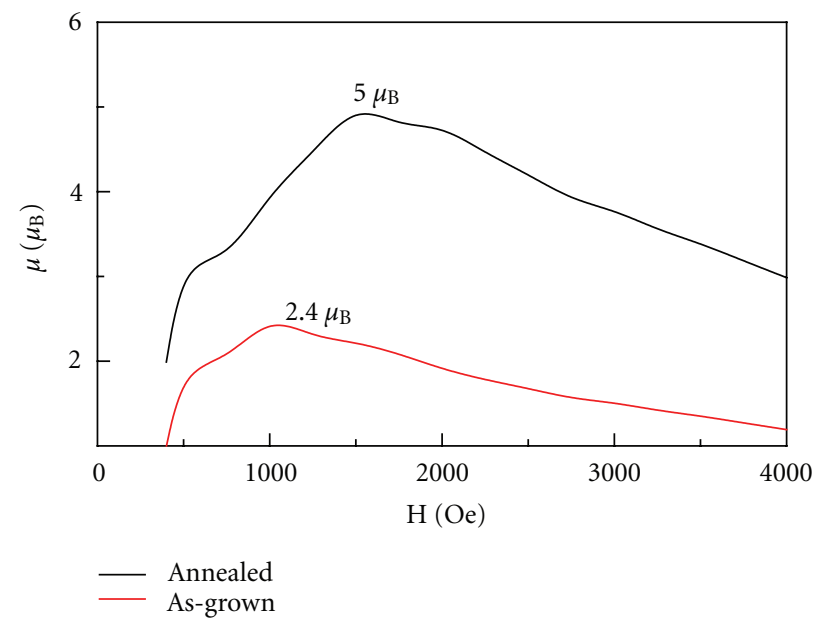

Figure 5: The magnetic conductivity of the as-grown and the annealed $\mathrm{ZnO}: \mathrm{Mn}$ Nws at room temperature with the applied magnetic field $\mathrm{H}$.

\section{Acknowledgment}

This work was supported in parts by the National Natural Science Foundation of China (nos. 60776004, 60976071).

\section{References}

[1] S. A. Wolf, D. D. Awschalom, R. A. Buhrman et al., "Spintronics: a spin-based electronics vision for the future," Science, vol. 294, no. 5546, pp. 1488-1495, 2001.

[2] S. Ghosh, V. Sih, W. H. Lau et al., "Room-temperature spin coherence in ZnO," Applied Physics Letters, vol. 86, no. 23, article 232507, 2005.

[3] T. Dietl, H. Ohno, F. Matsukura, J. Cibert, and D. Ferrand, "Zener model description of ferromagnetism in zinc-blende magnetic semiconductors," Science, vol. 287, no. 5455, pp. 1019-1022, 2000. 
[4] L. M. Sandratskii and P. Bruno, "Exchange interactions in $\mathrm{ZnMeO}(\mathrm{Me}=\mathrm{Mn}, \mathrm{Fe}, \mathrm{Co}, \mathrm{Ni})$ : calculations using the frozenmagnon technique," Physical Review B, vol. 73, no. 4, article 045203, 2006.

[5] L. Petit, T. C. Schulthess, A. Svane, Z. Szotek, W. M. Temmerman, and A. Janotti, "Electronic structure of transition-metal impurities in p-type ZnO," Physical Review B, vol. 73, no. 4, article 045107, 2006.

[6] N. A. Spaldin, "Search for ferromagnetism in transitionmetal-doped piezoelectric ZnO," Physical Review B, vol. 69, no. 12 , article 125201, 2004

[7] S. J. Han, J. W. Song, C. H. Yang et al., "A key to roomtemperature ferromagnetism in Fe-doped $\mathrm{ZnO}$ : $\mathrm{Cu}$," Applied Physics Letters, vol. 81, no. 22, p. 4212, 2002.

[8] C. Song, K. W. Geng, F. Zeng et al., "Giant magnetic moment in an anomalous ferromagnetic insulator: Co-doped $\mathrm{ZnO}$," Physical Review B, vol. 73, no. 2, article 024405, 2006.

[9] M. H. F. Sluiter, Y. Kawazoe, P. Sharma et al., "First principles based design and experimental evidence for a $\mathrm{ZnO}$-based ferromagnet at room temperature," Physical Review Letters, vol. 94 , no. 18, article 187204, 2005.

[10] D. A. Schwartz, K. R. Kittilstved, and D. R. Gamelin, "Aboveroom-temperature ferromagnetic $\mathrm{Ni} 2+$-doped $\mathrm{ZnO}$ thin films prepared from colloidal diluted magnetic semiconductor quantum dots," Applied Physics Letters, vol. 85, no. 8, p. 1395, 2004.

[11] N. A. Theodoropoulou, A. F. Hebard, D. P. Norton et al., "Ferromagnetism in Co- and Mn-doped ZnO," Solid-State Electronics, vol. 47, no. 12, pp. 2231-2235, 2003.

[12] S. W. Lim, D. K. Hwang, and J. M. Myoung, "Observation of optical properties related to room-temperature ferromagnetism in co-sputtered $\mathrm{Zn} 1-\mathrm{xCoxO}$ thin films," Solid State Communications, vol. 125, no. 5, pp. 231-235, 2003.

[13] K. Ueda, H. Tabata, and T. Kawai, "Magnetic and electric properties of transition-metal-doped $\mathrm{ZnO}$ films," Applied Physics Letters, vol. 79, no. 7, p. 988, 2001.

[14] D. P. Norton, S. J. Pearton, A. F. Hebard, N. Theodoropoulou, L. A. Boatner, and R. G. Wilson, "Ferromagnetism in Mnimplanted ZnO:Sn single crystals," Applied Physics Letters, vol. 82, no. 2, p. 239, 2003.

[15] K. Rode, A. Anane, R. Mattana, J. P. Contour, O. Durand, and R. LeBourgeois, "Magnetic semiconductors based on cobalt substituted ZnO," Journal of Applied Physics, vol. 93, no. 10, p. 7676, 2003.

[16] P. Sharma, A. Gupta, K. V. Rao et al., "Ferromagnetism above room temperature in bulk and transparent thin films of Mndoped ZnO," Nature Materials, vol. 2, no. 10, pp. 673-677, 2003.

[17] Z. Wang, X. Y. Ma, J. W. Song, and J. H. Yao, "Optical properties of $\mathrm{ZnO}$ and $\mathrm{Mn}$-doped $\mathrm{ZnO}$ nanocrystals fabrication by vapor phase transport processes," Nano-Micro Letters, vol. 1, no. 1, pp. 45-48, 2009.

[18] N. S. Norberg, K. R. Kittilstved, J. E. Amonette, R. K. Kukkadapu, D. A. Schwartz, and D. R. Gamelin, "Synthesis of colloidal $\mathrm{Mn} 2+: \mathrm{ZnO}$ quantum dots and high-Tc ferromagnetic nanocrystalline thin films," Journal of the American Chemical Society, vol. 126, no. 30, pp. 9387-9398, 2004.

[19] P. V. Radovanovic and D. R. Gamelin, "High-temperature ferromagnetism in $\mathrm{Ni} 2+$-doped $\mathrm{ZnO}$ aggregates prepared from colloidal diluted magnetic semiconductor quantum dots," Physical Review Letters, vol. 91, no. 15, article 157202, 2003.

[20] N. Theodoropoulou, A. F. Hebard, M. E. Overberg et al., "Unconventional carrier-mediated ferromagnetism above room temperature in ion-implanted (Ga, Mn)P:C," Physical Review Letters, vol. 89, no. 10, article 107203, 2002.

[21] G. Y. Ahn, S. I. Park, I. B. Shim, and C. S. Kim, "Mössbauer studies of ferromagnetism in Fe-doped $\mathrm{ZnO}$ magnetic semiconductor," Journal of Magnetism and Magnetic Materials, vol. 282, pp. 166-169, 2004. 

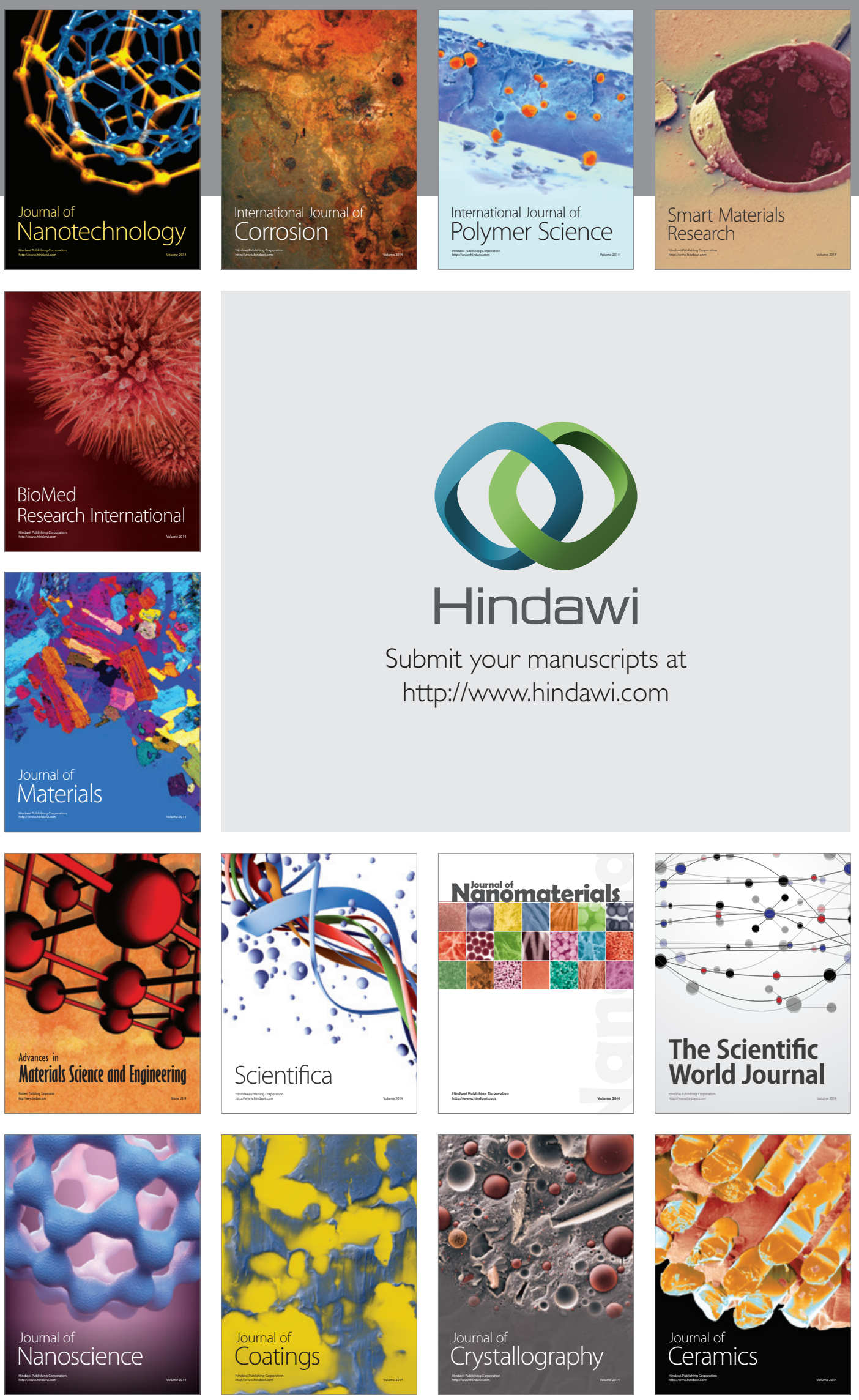

The Scientific World Journal

Submit your manuscripts at

http://www.hindawi.com

\section{World Journal}

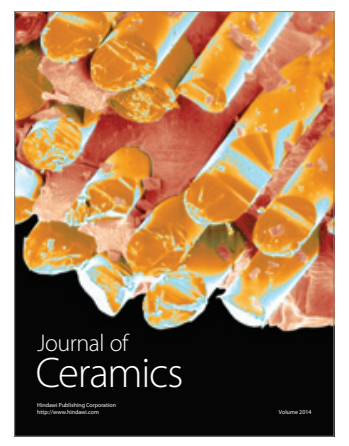

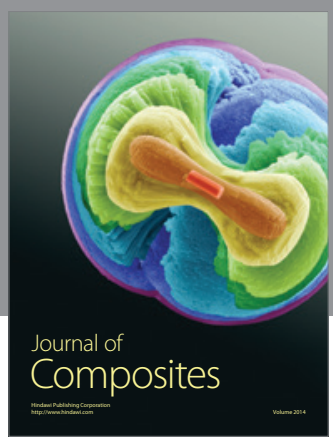
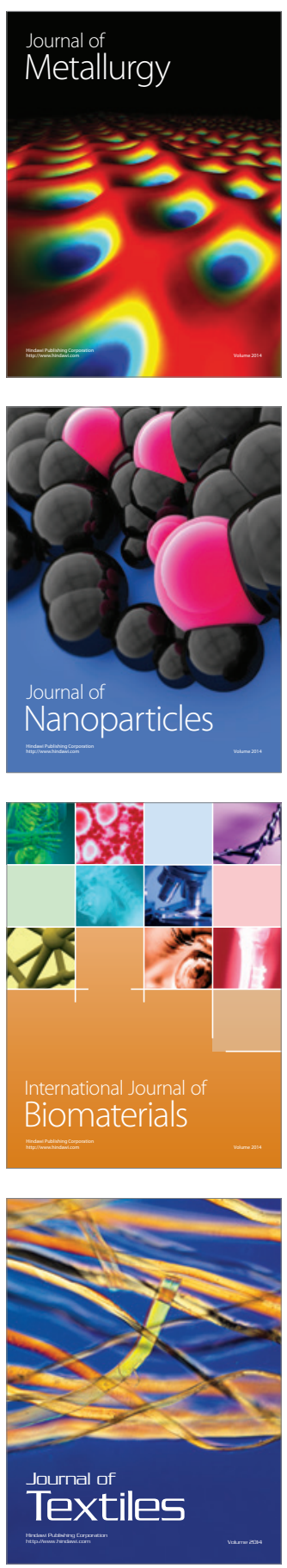